\title{
Final Progress Report
}

Nanostructured ceramics and composites for refractory applications in coal gasification

Oct. 1, 2001 - Jan. 23, 2005

Paul Brown

Issued Jan. 31, 2005

Award number: DE-FG26-01NT41278

Submitting Organization: Penn State University 


\section{Disclaimer:}

This report was prepared as an account of work sponsored by an agency of the United States Government. Neither the United States Government nor any agency thereof, nor any of their employees, makes any warranty, express or implied, or assumes any legal liability or responsibility for the accuracy, completeness or usefulness of any information, apparatus, product or process disclosed, or represents that its use would not infringe privately owned rights. Reference herein to any specific commercial product, process, or service by trade name, trademark, manufacturer, or otherwise does not necessarily constitute or imply its endorsement, recommendation, or favoring by the United States Government or any agency thereof. The views and opinions of authors expressed here do not necessarily state or reflect those of the United States Government or any agency thereof. 


\section{Abstract:}

A class of ceramics, capable of exhibiting low coefficients of thermal expansion and catalytic properties was investigated. Investigations were directed towards nanoengineering of NZP ceramics and NZP-based composites by chemical means by controlling their compositions and processing variables. $\mathrm{NaZr}_{2}\left(\mathrm{PO}_{4}\right)_{3}$ (NZP) was synthesized by combining water-soluble precursors leading to the precipitation of a gel that was dried, calcined, pressed into pellets, then fired at $850^{\circ} \mathrm{C}$. Without chemical additives, the resulting ceramic comprised pores ranging in size from approximately 25 to $50 \mathrm{~nm}$ and a surface area of about $30 \mathrm{~m}^{2} / \mathrm{g}$. Hydroxyapatite, which has a needle-like morphology, was mechanically mixed with the calcined gel to template NZP crystallization. What resulted was a coarsening of the pore structure and a decrease in surface area. When copper nitrate was added to the solution during synthesis, the resulting ceramic underwent shrinkage upon firing as well as an increase in strength. HAp and copper additions combined resulted in $40 \%$ volume shrinkage and a doubling of the tensile strength to $16 \mathrm{MPa}$. A very different type of porosity was achieved when silica was partly substituted for phosphorous in the NZP structure. $\mathrm{Na}_{3} \mathrm{Zr}_{2}\left(\mathrm{Si}_{2} \mathrm{P}\right) \mathrm{O}_{12}$ (NASCION) was synthesized in the same manner as NZP, but the fired ceramic possessed a reticulated pore structure comprising large cavities ranging in size from 5 to $50 \mu \mathrm{m}$. The NASCION ceramic either shrank or expanded upon firing depending on when the silica was added during synthesis. When the silica precursor (amorphous, precipitated silica) was added before the calcining step, the pressed pellets expanded during firing, whereas they shrank when the silica was added after the gel was calcined. The observed dilation increased with increasing calcining temperature and particle size, up to $26 \%$. The contraction of the ceramic when fired increased with increasing calcining temperature and a greater surface area of the gel. Direct addition of Silica fiber was only 
modestly beneficial. Fiber addition combined with controlled densification resulted in the greatest improvement in strength. Ion exchange properties of NASICON were established for $\mathrm{Cs}, \mathrm{Pb}$, and $\mathrm{Cd}$. It was found that the extent of ion exchange depended on ion size and that $\mathrm{Cd}$ could be fully exchanged into NASICON. Catalytic activity of $\mathrm{Cu}$ and $\mathrm{Ag}$ substituted compositions were determined and it was found that Ag substitution reduced the temperature at which carbon black could be oxidized. However, Ag substitution results in the formation of zircon. Ion conductivity of NASCION was determined and it was found to compare well with other ionic conductors. 
Table of Contents

I. Title page 1

II. Disclaimer 2

III. Abstract 3

$\begin{array}{lll}\text { IV. } & \text { List of graphical materials } & 6\end{array}$

$\begin{array}{lll}\text { V. Objective } & 7\end{array}$

VI. Executive Summary 9

$\begin{array}{ll}\text { VII. Experimental results and discussion } & 11\end{array}$

$\begin{array}{lr}\text { VIII. Conclusions } & 19\end{array}$

$\begin{array}{ll}\text { XI. Tables } & 20\end{array}$

$\begin{array}{lll}\text { X. Figures } & 22\end{array}$ 


\section{List of graphical materials}

Figure 1. Nozzle configuration.

Figure 2. Spinning apparatus.

Figure 3. Highly crystalline phase-pure NZP.

Figure 4. Fibers grown in situ within the pore structure of the ceramic.

Figure 5. Percent uptake of the cation into the NASCION structure as a function of ionic radius.

Figure 6. TGA curves for the NASICON composition (Nas600). Curves for compositions containing 5\% $\mathrm{CuO}$ and clean NASICON (no additives) indicate no reduction of the oxidation temperature at which the carbon black begins to oxidize associated with copper doping.

Figure 7. The $\operatorname{Nas}(1 / 3 \mathrm{Ag})$ and $\operatorname{Nas}(2 / 3 \mathrm{Ag})$ compositions formed zircon as the only crystalline phase.

Figure 8 . The XRD pattern of Nas( $600 ; 5 \%$ fiber).

Figure 9. Ag can substitute completely into the NZP structure and the XRD pattern of phasepure $\mathrm{AgZr}_{2}\left(\mathrm{PO}_{4}\right)_{3}$ is shown.

Figure 10. Nas600 (5\%CuO, 5\%Fibres) shows well developed crystallites.

Figure 11. A typical plot log-conductivity vs log-frequency from measurements taken at $80^{\circ} \mathrm{C}$. The DC conductivity was taken as the value corresponding to the frequency independent.

Figure 12. Conductivities at a frequency of $20,000 \mathrm{~Hz}$ plotted as a function of inverse temperature to establish the activation energy as a measure of mobility of the sodium ion. 
V. Objective

The class of ceramics typified by $\mathrm{NaZr}_{2}\left(\mathrm{PO}_{4}\right) 3$ ("NZP") are thermally stable to $1500^{\circ} \mathrm{C}$ $\left(2700^{\circ} \mathrm{F}\right)$ while exhibiting low to zero coefficients of thermal expansion (CTE's) up to $1000^{\circ} \mathrm{C}$ $\left(\sim 1800^{\circ} \mathrm{F}\right)$ or more. Low CTE values confer thermal shock resistance to NZP ceramics. Further, NZP-based ceramics and composites exhibit very low thermal conductivities and some compositions appear to have catalytic properties that promote the oxidation of hydrocarbons. This combination of properties makes NZP-based ceramics particularly attractive for applications requiring thermal management, thermal shock resistance, exposure to aggressive gaseous environments, and gas clean up.

The objective of the present program is to prepare monolithic NZP-type ceramics in ways that make them attractive for use in refractory applications, in hot gas filtering technologies by controlling their compositions and porosities at the atomic level. An objective is to use gelcasting because, although a bench-level study is proposed, it is anticipated that the preparative processes used are amenable to scale-up. Castability is believed to provide an economical route to the production of complex, and near net shapes as, for example, in the formation of candle filters.

In the first phase of the program the mechanistic paths to NZP formation was determined. Specific emphasis was placed on identifying preparative routes that lead directly to the formation of NZP without forming intermediates. Because small grain sizes can be produced by chemical formation of NZP, the relationship between chemistry and grain growth was explored in detail. In a second phase of the program controlled NZP and NASICON microstructures were produced. The final objective explored was the formation of nanostructured NZP matrix composites. This 
is to ensure that desirable properties can be realized by engineering at the atomic level by incorporating fibers into the microstructures. Finally, conductivities were determined 


\section{Executive Summary}

The synthesis of NZP-based ceramics has been established. Two compositions were explored, each having unique processing routes that impart to them their own unique properties. The first is the NZP ceramic having composition $\mathrm{NaZr}_{2}\left(\mathrm{PO}_{4}\right)_{3}$. The second is a silicon substituted NZP ceramic having composition $\mathrm{Na}_{3} \mathrm{Zr}_{2}\left(\mathrm{Si}_{2} \mathrm{P}\right) \mathrm{O}_{12}$. Both were made to possess large amounts of porosity suitable for hot gas filtering applications.

For the NZP ceramic having composition $\mathrm{NaZr}_{2}\left(\mathrm{PO}_{4}\right)_{3}$, two types of additives were used: (1) HAp and (2) $\mathrm{CuO}$. Precipitated hydroxyapatite constitutes needles but was dissolved into the NZP structure during firing altering the pore morphology of the resulting ceramic. $\mathrm{CuO}$ additions stimulated densification during firing imparting greater strength to the ceramic, though at the expense of internal surface area. The fine pore structure measures about 50nm and less and contributes approximately $30 \mathrm{~m}^{2} / \mathrm{g}$ of internal surface area to the fired ceramic component. The addition of HAp coarsens the pore structure and reduces the internal surface area. Further additions of HAp were found to decrease internal surface area but do not contribute to densification.

$\mathrm{CuO}$ additions were shown to both further increase the amount of shrinkage the pellets undergo during firing as well as further coarsen the microstructure. Larger grains and grain boundaries indicated that densification had occurred resulting in higher strengths, but low internal surface area.

NASCION (Na Super Ionic Conductor) has the composition $\mathrm{Na}_{3} \mathrm{Zr}_{2}\left(\mathrm{Si}_{2} \mathrm{P}\right) \mathrm{O}_{12}$ and is noted for its ionic conductivity. However, the synthesis routes established for this compound rendered the resulting ceramic porous with its own unique microstructure. Two different routes in making porous NASCION were explored. The first started with a precipitated gel to which amorphous 
silica was added. The slurry was dried, calcined, milled and pressed into pellets that were fired at $1100^{\circ} \mathrm{C}$ for 5 hours. The resulting ceramic was observed to expand substantially during firing. This expansion was greater at higher calcination temperatures. The second route entailed not adding the silica until after the gel was calcined, which resulted in the ceramic shrinking during firing. This shrinkage was greater at high calcinations temperatures.

The reticulated microstructures of these NASCION ceramics constituted a flowering of welldeveloped crystals $(1-5 \mu \mathrm{m})$ that formed clusters. These clusters were connected in a way to form 3-dimmensionally interconnected structures that left a network of empty spaces ranging in size from 5 to $50 \mu \mathrm{m}$.

Properties of NASICON ceramics can be modified by in situ fiber formation or formation in the presence of fibers. MASICON shows the ability to exchange ions and can sequester toxic and heavy metal ions such as Cd. Doping the NASICON composition with Ag changes it to the zircon structure, but shows the ability to reduce the temperature at which particulate carbon is oxidized. NASICON also shows the ability to act as an ionic conductor. 
VII. Experimental Results and Discussion

\section{Production of Silica Fibers}

Tetraethylorthosilcate (TEOS; MW = $208.33 \mathrm{~g} \mathrm{~mol}^{-1}$ ) was mixed with DI water and ethanol to form a viscous silicate solution that could be drawn into fibers. The $r$-ratio, defined as the molar ratio of water-to-TEOS, was varied from 1 to 2 . Ethanol and water were proportioned to ensure that a clear single-phase solution persisted. All solutions were acid catalyzed with 2 or 3 drops of $1 \mathrm{M} \mathrm{HCl}$. This produced working recipe for the consistent production of sol-gel fibers.

The specimen cup containing the clear sol-gel solution was sealed with a lid. The solution was then allowed to stand undisturbed for 5 days to age. Afterwards, the lid was removed to allow evaporation of the ethanol. After about $1 \frac{1}{2}$ days, the solution thickened enough to draw fibers. Special care was taken at this stage so as not to let the solution gel completely. Once the solution possessed the viscosity of honey, possibly a little thicker, the solution was transferred to two aluminum nozzles that were designed to fit into the centrifuge. Schematics of the apparatus used to extrude fibers using centrifugal force are presented in Figures 1 and 2.

Surrounding the centrifuge is a sheet metal tube that is $2 \mathrm{ft}$ high and $1 \frac{1 / 2}{\mathrm{ft}}$. in diameter. The inside was first covered with wax paper. The motor setting was set at $3 / 4$ power. Once turned on, the nozzles begin to spin, thereby extruding the fiber onto the wax paper. As this process occurs, the tube is slowly raised so as to catch the extruded fiber along the full length of the tube or until the material in the nozzles runs out. After about 12 hours of drying, the fibers are lifted off the wax paper then stored. 


\section{Production of NZP/Fiber Composites}

The silica-gel fibers, once made, were incorporated into the NZP and NASICON compositions. After the NZP and NASICON gels were calcined at their respective calcining temperatures, the fibers were added to the powders in the amount of $5 \mathrm{wt} \%$. The mixture was then roller-milled in ethanol for approximately 3 hours then dried over night in a drying oven set at around $100^{\circ} \mathrm{C}$. The powder was then pressed into pellets and fired at their respective firing temperatures.

It was desired to establish whether directly incorporating fibers would enhance the mechanical properties of the NZP and NASICON ceramics. The first materials to be investigated were the NZP composites containing untreated admixed silica gel fibers and admixed fibers fired at $600^{\circ}$ and $1100^{\circ} \mathrm{C}$. Table I shows the results of testing the NZP composites in diametral compression. Compared to those strengths previously determined for samples not containing admixed fibers, present strengths were lower for those compositions containing $\mathrm{CuO}$ and/or HAp. Overall, there was a significant improvement in the strengths of NZP ceramics was not realized by incorporating silica fibers. Additionally, significant "endcapping" was observed in some of the NZP samples containing fibers thus indicating that processing of applied materials to be complicated. Nonetheless, the presence of admixed silica fibers did not appear to alter the phases present, in particular the presence of fibers did not promote the transformation of the NZP structure to NASICON. X-ray diffraction analyses showed highly crystalline phase-pure NZP in all compositions studied, as illustrated in Figure 3. 


\section{NASICON and in situ Fiber Growth}

It was discovered that when NASICON was allowed to imbibe water, fibers appeared within the open cavities that are prevalent within the microstructure of these ceramics. Because this provides a novel mechanism for controlling the pore structures, an effort was made to reproduce these results and to determine the mechanism responsible for fiber growth. Figure 4 presents a SEM micrograph showing these fibers and the extent of their growth. SEM analysis on these "hydrated" NASICON ceramics have revealed that the areas containing such fibers are difficult to find and are most likely relegated to isolated and discrete portions of the ceramic pellet. It is hypothesized that the area in which fiber growth occurs is along a plane parallel to and midway between the faces of the pellet. Outside this area, evaporation was believed to eliminate pore water, thereby decreasing the water retention time needed for fiber growth.

A variety NASICON ceramics were made for testing of this hypothesis. Nas $+\mathrm{S}$ and NasS samples that were calcined at $500^{\circ}, 600^{\circ}$ and $700^{\circ} \mathrm{C}$ were synthesized. A protocol was established for the hydration of porous NASCION. First, water was added to the pellet dropwise from a disposable pipette and was imbibed by capillary forces. This was repeated until further water was no longer adsorbed. The saturated pellets were then placed into a sealed vial and were left undisturbed for about a week to permit fiber growth. The pellets were then dried in a $120^{\circ} \mathrm{C}$ oven overnight then fractured for analysis by SEM. Processing in a hydrothermal bomb at a hydrostatic pressure 25,000 psi for two hours was found to produce a denser growth of fibers. However, shorter processing times at lower pressures, such as 2800 psi for 5 minutes did not produce fibers. Unfortunately, no fibers were found during inspection of these "hydrated" samples. Table I shows that there was minimal differences in strengths between those that were hydrated (Nas600Hy) and those that were not (Nas600). 


\section{NASCION/Fiber Composites}

The use of admixed silica fibers in NASICON compositions were also evaluated. NASICON samples of intermediate calcination temperature (i.e. $600^{\circ} \mathrm{C}$ ) containing $5 \%$ fibers were broken in diametral compression. The results, presented in Table I, show that such fibers (calcined at $1100^{\circ} \mathrm{C}$ ) gave improved strengths; strengths increased from 8.5 MPa to $12.5 \mathrm{MPa}$. SEM showed that Nas600 samples fired with 5\% fibers produced a large amount of a glassy phase. Therefore, $\mathrm{CuO}$ was added to act on this glassy phase to decrease its melting point to the extent of encouraging liquid phase sintering. This processing strategy resulted in the largest strength increases. Samples containing 5\% $\mathrm{CuO}$ and 5\% fibers produced strengths up to 21 MPa.

As opposed to Nas600, (Nas+S) samples that showed dilation in a previous study, the same Nas600 pellets containing 5\% CuO and 5\% fibers contracted. This increased density may have contributed to the increased strengths observed. An alternative explanation is that the silica fibers were added after the calcination step and prior to milling. This was the case for the (NasS) samples of the previous study where the silica was also added after the calcination step. The previous study also has shown that (Nas-S) samples contracted with firing at $1100^{\circ} \mathrm{C}$. Thus, it was assumed that $\mathrm{CuO}$ and fiber additions to these samples would increase further the degree of densification as it did with the Nas+S:600 samples. Therefore, (Nas-S:700) samples, that were shown previously to undergo the greatest amount of shrinkage, were modified to include $5 \%$ $\mathrm{CuO}$ and 5\% fibers in their composition. The results, shown in Table I, reveal strength of 14.5 $\mathrm{MPa}$, which is not as great as that of the (Nas+S: 600) sample containing $\mathrm{CuO}$ and Fibers. 


\section{Ion Exchange Properties of NASICON}

The NASICON crystal structure is amendable to three-dimensional sodium migration. The literature has also indicated ion-exchangeability with the sodium ion. Therefore, experiments were set up to test the ion-exchangeability of NASICON with toxic heavy metal cations. The NASICON used was porous and made in the same manner as described previously. Two general experimental protocols were carried out. The first employed immersing whole pellets in a $20 \mathrm{~mL}$ solution containing the heavy metal cation. The second experiment pellets crushed into a course powder were immersed. The solutions used were from stock $1000 \mathrm{mg} / \mathrm{L}$ solutions of cadmium acetate, lead nitrate and cesium chloride. The results are presented in Table II. From the results presented in Table II, a trend between the size of the cation and the degree to which the cation exchanges with sodium in the porous NASICON ceramic can be observed. The larger the cation, the less it was exchanged. The smaller cations exhibited much more success in being ionexchanged with sodium. With cadmium, $\mathrm{Cd}^{2+}$, the smallest cation tested, up-take with crushed NASICON was $100 \%$. This result suggests the potential application for NASICON in the area of heavy metal immobilization.

Figure 5 plots the \%-uptake of the cation as a function of ionic radius. Extrapolating the trend to even smaller cations, such as to lithium, suggests complete substitution into the NASICON structure. This suggests the possible opportunity for producing a lithium ionic conductor for use in lithium batteries. The high temperature stability of NASICON could be beneficial for power generation at elevated temperatures, as well. 


\section{Catalytic Activity of Doped NASCION and NZP}

Compositions of NZP and NASICON ceramics containing 5\% silica fibers were doped with either copper or silver. This was done to establish whether catalytic activity could be realized in a ceramic containing base metals. Normally, $\mathrm{CuO}$ is a standard additive to increase strength and density but was also tested for its catalytic activity. Silver was added to replace sodium and therefore was batched accordingly. The application of porous NZP/NASICON as a filter/catalyst was anticipated to depend on how well it oxidizes carbon soot. Experiments were set up to test this ability. Carbon black, used as the soot source, was first mixed with ethanol to form a suspension. The carbon black/ethanol slurry was then added drop wise onto the NZP/NASICON pellet using a disposable pipette. Slurry was added until it pooled up on the surface. The impregnated pellets were then placed on a napkin to dry. Afterwards, the pellets were crushed into a powder and analyzed for weight-loss as a function of temperature using the TGA. The TGA curves are shown in Figure 6 for just the NASICON composition (Nas600). Close inspection of the $5 \% \mathrm{CuO}$ and clean (no additives) curves reveals no change in terms of the temperature at which the carbon black begins to oxidize. Therefore, copper does not appear to effectively catalyze the oxidation of carbon black.

A reduction in oxidation temperature of carbon black was observed for the NASICON composition containing silver. This particular sample was batched to have the composition $\mathrm{Na}_{2} \mathrm{AgZr}_{2}\left(\mathrm{Si}_{2} \mathrm{P}\right) \mathrm{O}_{12}$ where $1 / 3$ of the $\mathrm{Na}^{+}$is replaced with $\mathrm{Ag}^{+}$. According to Figure 6, this sample shows a reduction in temperature of around $70^{\circ} \mathrm{C}$. However, the ceramic supporting the silver was found not to posses the NZP structure, rather the pellet was comprised of zircon, $\mathrm{ZrSiO}_{4}$. The XRD patterns in Figure 7 show that the $\mathrm{Nas}(1 / 3 \mathrm{Ag})$ and $\mathrm{Nas}(2 / 3 \mathrm{Ag})$ compositions 
formed zircon as the only crystalline phase. It should be noted, though, that these compositions also included $5 \% \mathrm{CuO}$ and $5 \%$ silica fiber as well. Figure 8 presents the XRD patterns of $\operatorname{Nas}(600 ; 5 \%$ fiber $)$ and $\mathrm{Nas}(600 ; 5 \% \mathrm{CuO}, 5 \%$ fiber $)$. It can be seen that these compositions formed the NASICON structure. However, $\operatorname{Nas}(600 ; 5 \% \mathrm{CuO}, 5 \%$ fiber $)$ is bi-phasic and also contains zircon. Thus, it appears that the replacement of just one sodium atom with silver destabilizes the NASICON structure causing zircon to form instead. Alternatively, Ag can substitute completely into the NZP structure. This results in the formation of phase-pure $\mathrm{AgZr}_{2}\left(\mathrm{PO}_{4}\right)_{3}$, as shown in Figure 9.

\section{NASICON as an Ionic Conductor}

The porous NASICON ceramics made during the previous studies was anticipated to not likely possess a practical ionic conductivity. However, when the NASICON was found to densify to a degree not previously observed, it became appropriate to measure ionic conductivity. The pellet tested was of composition Nas600(5\%CuO, 5\%Fibres) and exhibited high strength (21 $\mathrm{MPa}$ ), and comprised of well developed crystallites, as shown by the SEM micrograph in figure 10. Gold was sputtered on the two parallel faces of the pellets to act as electrodes. AC impedance spectroscopy was used and resistance across the pellet was measured within a frequency range of $100 \mathrm{~Hz}$ to $5 \mathrm{MHz}$ and at temperatures ranging from $25^{\circ} \mathrm{C}$ to $225^{\circ} \mathrm{C}$. The raw data were then converted to log-conductivity vs log-frequency plots by taking into account the dimensions of the pellets. A typical plot of this sort, from measurements taken at $80^{\circ} \mathrm{C}$, is presented in figure 11. The DC conductivity was taken as the value corresponding to the frequency independent plateau, as shown in Figure 11. A frequency of $20,000 \mathrm{~Hz}$, from which a conductivity value was taken, was used at all temperatures. These conductivities were then 
plotted as a function of inverse temperature to establish the activation energy as a measure of mobility of the sodium ion. This plot is shown in Figure 12. The resulting conductivity and activation energy predicted at $300^{\circ} \mathrm{C}$ for $\operatorname{Nas} 600(5,5)$ compares well with other sodium ionic conductors made in other studies. These comparisons are shown in Table III. Considering that the Nas600(5,5) pellets contain roughly 40 to $50 \%$ porosity and are bi-phasic, the conductivity value obtained is reasonable. According to ion exchangeability studies, it may be feasible to replace the $\mathrm{Na}^{+}$with $\mathrm{Li}^{+}$to make lithium ionic conductors for lithium batteries. It would be appropriate to test this theory in a future program.

Lithium substituted NASICONs, or LISICONs, were synthesized. Five compositions were explored: (1) $\mathrm{Li}_{3} \mathrm{Zr}_{2}\left(\mathrm{Si}_{2} \mathrm{P}\right) \mathrm{O}_{12} ; 5 \%$ fiber, (2) $\mathrm{Li}_{3} \mathrm{Zr}_{2}\left(\mathrm{Si}_{2} \mathrm{P}\right) \mathrm{O}_{12} ; 5 \% \mathrm{CuO}, 5 \%$ fiber, (3) $\mathrm{Li}_{3}\left(\mathrm{Zr}_{1.5} \mathrm{Ti}_{0.5}\right)\left(\mathrm{Si}_{2} \mathrm{P}\right) \mathrm{O}_{12} ;$ (4) $\mathrm{Li}_{3}\left(\mathrm{Zr}_{1.0} \mathrm{Ti}_{1.0}\right)\left(\mathrm{Si}_{2} \mathrm{P}\right) \mathrm{O}_{12}$, and (5) $\mathrm{Li}_{3}\left(\mathrm{Zr}_{0.5} \mathrm{Ti}_{1.5}\right)\left(\mathrm{Si}_{2} \mathrm{P}\right) \mathrm{O}_{12}$. All five compositions densified, were black in color and were comprised predominantly zircon, $\mathrm{ZrSiO}_{4}$. In spite of this, future studies to measure the ionic conductivity of these lithium-containing zircon ceramics may be warranted. It is possible that these may exhibit conductivity via the grain boundaries, which may contain the mobile lithium cations. 


\section{Conclusions.}

The bench-level results obtained in this study suggest various applications for NZP and NASICON ceramics in applications involving coal gasification. These include their uses in separation technology where it is desirable to separate gasified coal from both volatile and nonvolatile components. It has been established that strengths of low thermal expansion ceramics can be improved and that pore structures can be controlled.

Additional work has demonstrated that ceramics within in these classes may act as ionic conductors, as catalysts for the oxidation or carbon and as hosts for selected heavy metal ions.

Future work should concentrate on refining compositions specific to these applications and demonstration of the ability of the ceramics to perform at the pilot level. 
XI. Tables

Table 1. Diametral strengths of composites incorporating silica fibers NZP

\section{Composition}

$5 \% \mathrm{CuO}+$ fibers, uncalcined

$5 \% \mathrm{CuO}+5 \% \mathrm{HAp}+$ fibers uncalcined

5\% CuO+ fibers, calcined@600C

5\% CuO + 5\% HAp + fibers calcined @ 1100C

Fibers only calcined at $1100 \mathrm{C}$
Average Strength, MPa

8.47

6.90

5.42

8.18

5.58

8.67

12.46

8.65

12.40

11.92

20.94

10.67

14.58 
Table II Heavy metal uptake

\begin{tabular}{|l||l|l|l|l|l|l|}
\hline $\begin{array}{l}\text { Metal } \\
\text { Cation }\end{array}$ & $\begin{array}{l}\text { Ionic } \\
\text { Radius } \\
{[\AA]}\end{array}$ & $\begin{array}{l}\text { Pellet } \\
\text { Initial } \\
\text { Conc. } \\
{[\mathrm{mg} / \mathrm{L}]}\end{array}$ & $\begin{array}{l}\text { Pellet } \\
3 \text { days } \\
{[\mathrm{mg} / \mathrm{L}]}\end{array}$ & $\begin{array}{l}\text { Pellet } \\
7 \text { days } \\
{[\mathrm{mg} / \mathrm{L}]}\end{array}$ & $\begin{array}{l}\text { Crushed } \\
\text { Initial } \\
\text { Conc. } \\
{[\mathrm{mg} / \mathrm{L}]}\end{array}$ & $\begin{array}{l}\text { Crushed } \\
25 \text { days } \\
{[\mathrm{mg} / \mathrm{L}]}\end{array}$ \\
\hline $\mathrm{Cs}^{+}$ & 1.67 & 1080 & 1000 & 1080 & --- & --- \\
\hline $\mathrm{Pb}^{2+}$ & 1.20 & 980 & 860 & 690 & 1135 & 364 \\
\hline $\mathrm{Cd}^{2+}$ & 0.97 & 1050 & 700 & 300 & 1089 & $<1$ \\
\hline
\end{tabular}

Table III Ionic conductivities at $300^{\circ} \mathrm{C}$.

\begin{tabular}{|l|l|l|}
\hline Ceramic & $\sigma[\mathrm{ohm}-1 \mathrm{~cm}-1]$ & $\mathrm{E}[\mathrm{eV}]$ \\
\hline \hline$\beta$-Alumina & 0.08 & 0.25 \\
\hline $\mathrm{Na}_{2} \mathrm{O} . \mathrm{Ga}_{2} \mathrm{O}_{3}$ & 0.03 & 0.27 \\
\hline $\mathrm{Na}_{3} \mathrm{Zr}_{2}\left(\mathrm{Si}_{2} \mathrm{P}\right) \mathrm{O}_{12}$ & 0.45 & 0.20 \\
\hline $\mathrm{Na}_{3.2} \mathrm{Zr}_{1.3} \mathrm{Si}_{2.2} \mathrm{P}_{0.8} \mathrm{O}_{10.5}$ & 0.22 & 0.17 \\
\hline $\mathrm{Nas} 600(5,5)$ & $\mathbf{0 . 0 4}$ & $\mathbf{0 . 3 4}$ \\
\hline
\end{tabular}


X. Figures

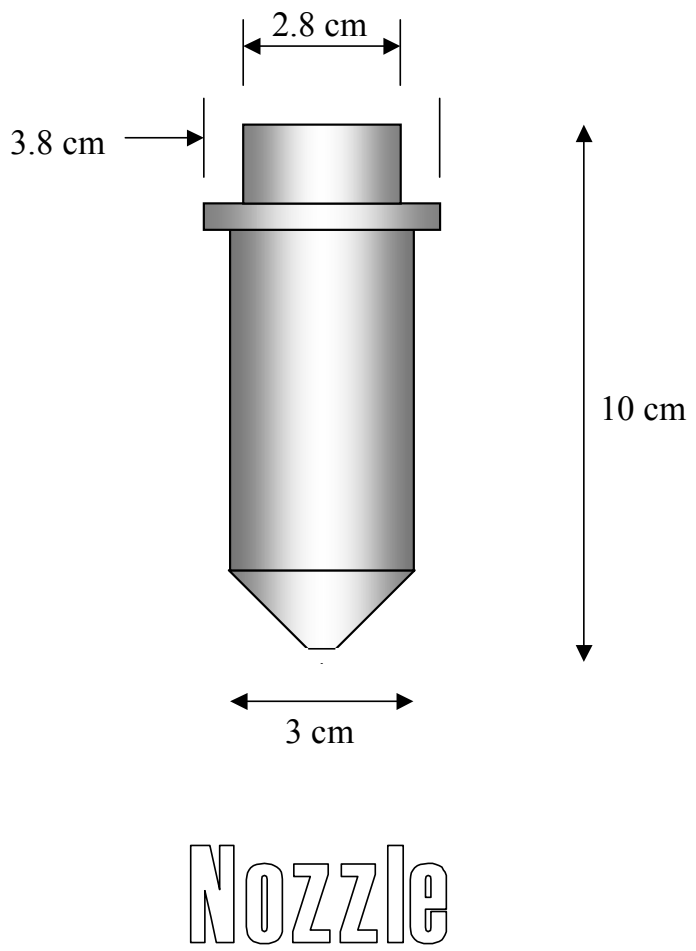

Figure 1. Nozzle configuration 


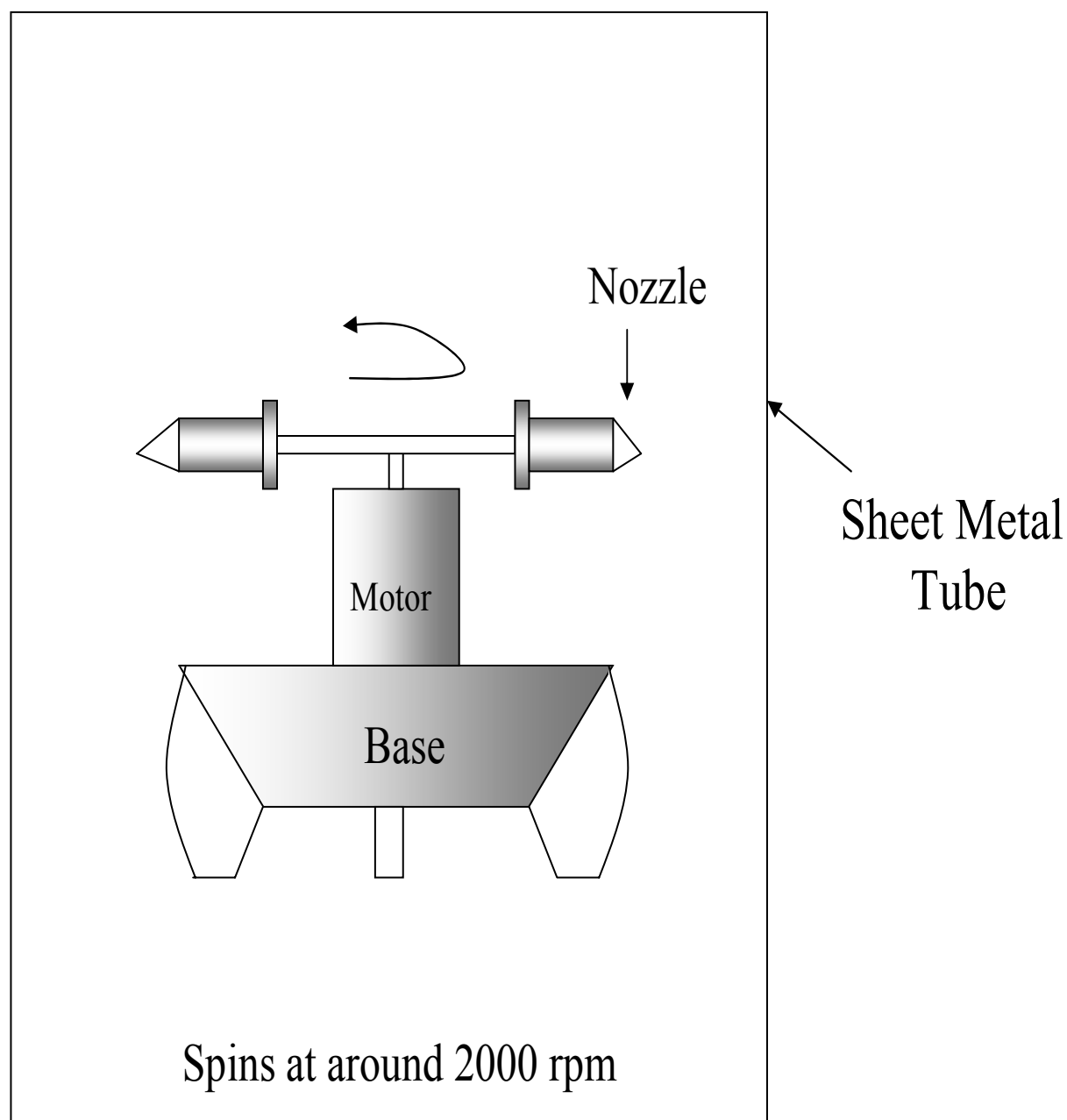

Figure 2. Spinning apparatus 


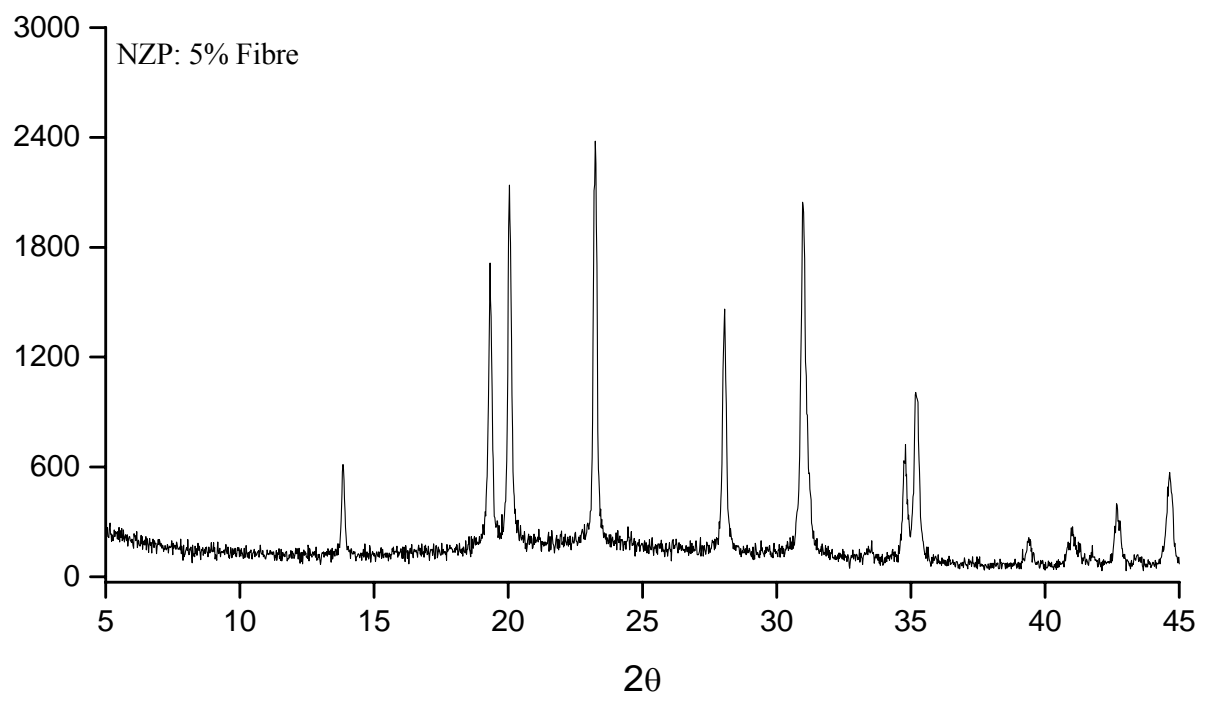

Figure 3

Highly crystalline phase-pure NZP . 


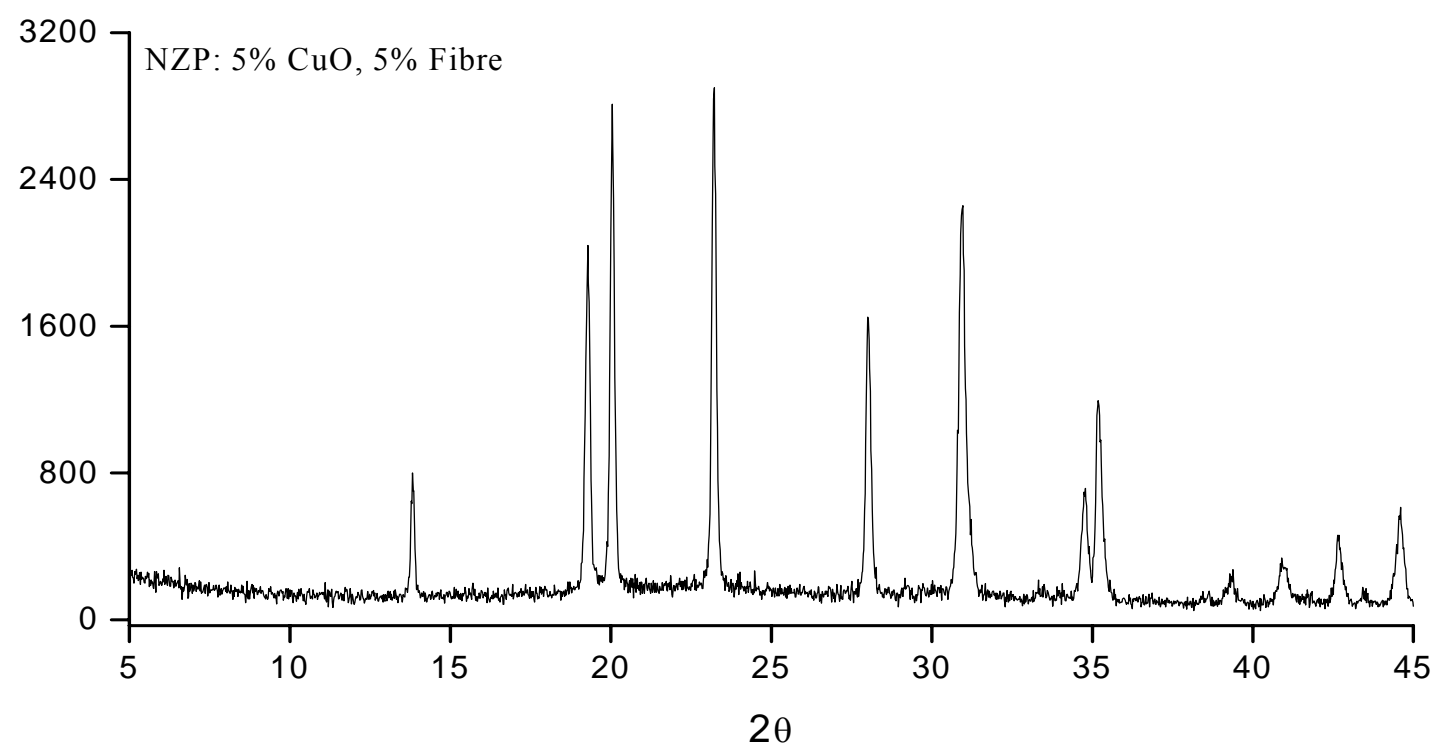

Figure $3 b$

Highly crystalline phase-pure NZP. 


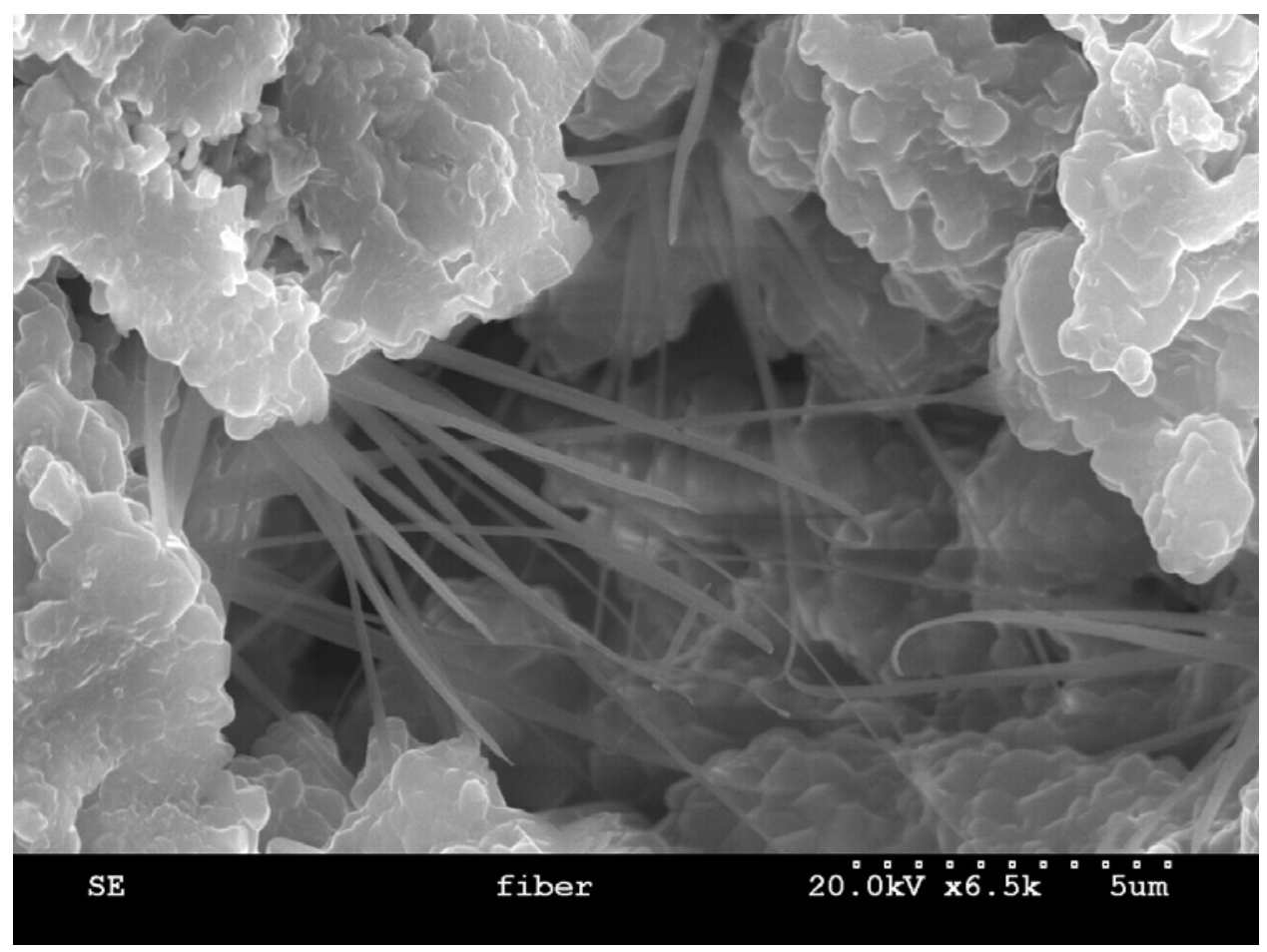

Figure 4

Fibers grown in situ within the pore structure of the ceramic. 


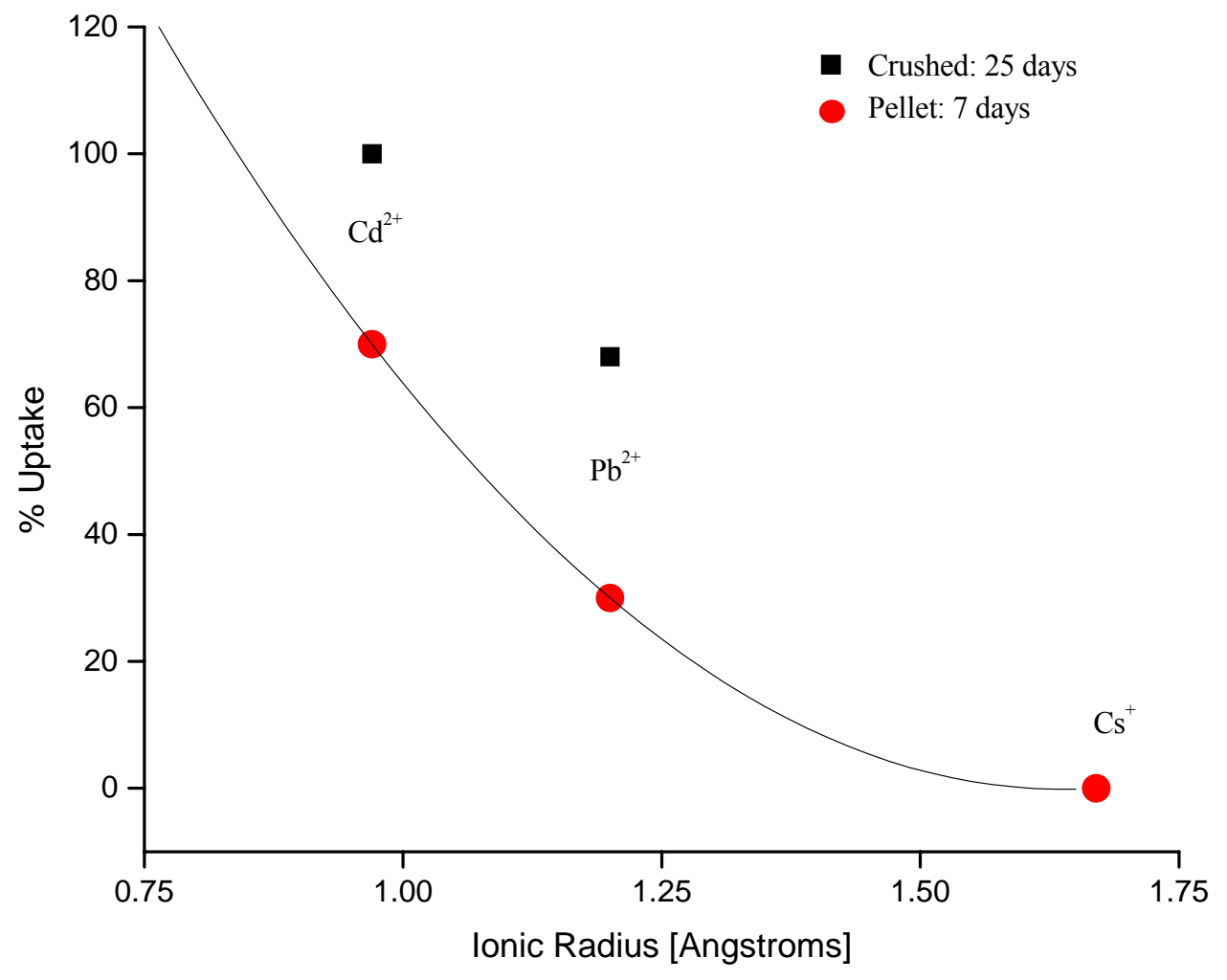

Figure 5

Percent uptake of the cation into the NASCION structure as a function of ionic radius. 


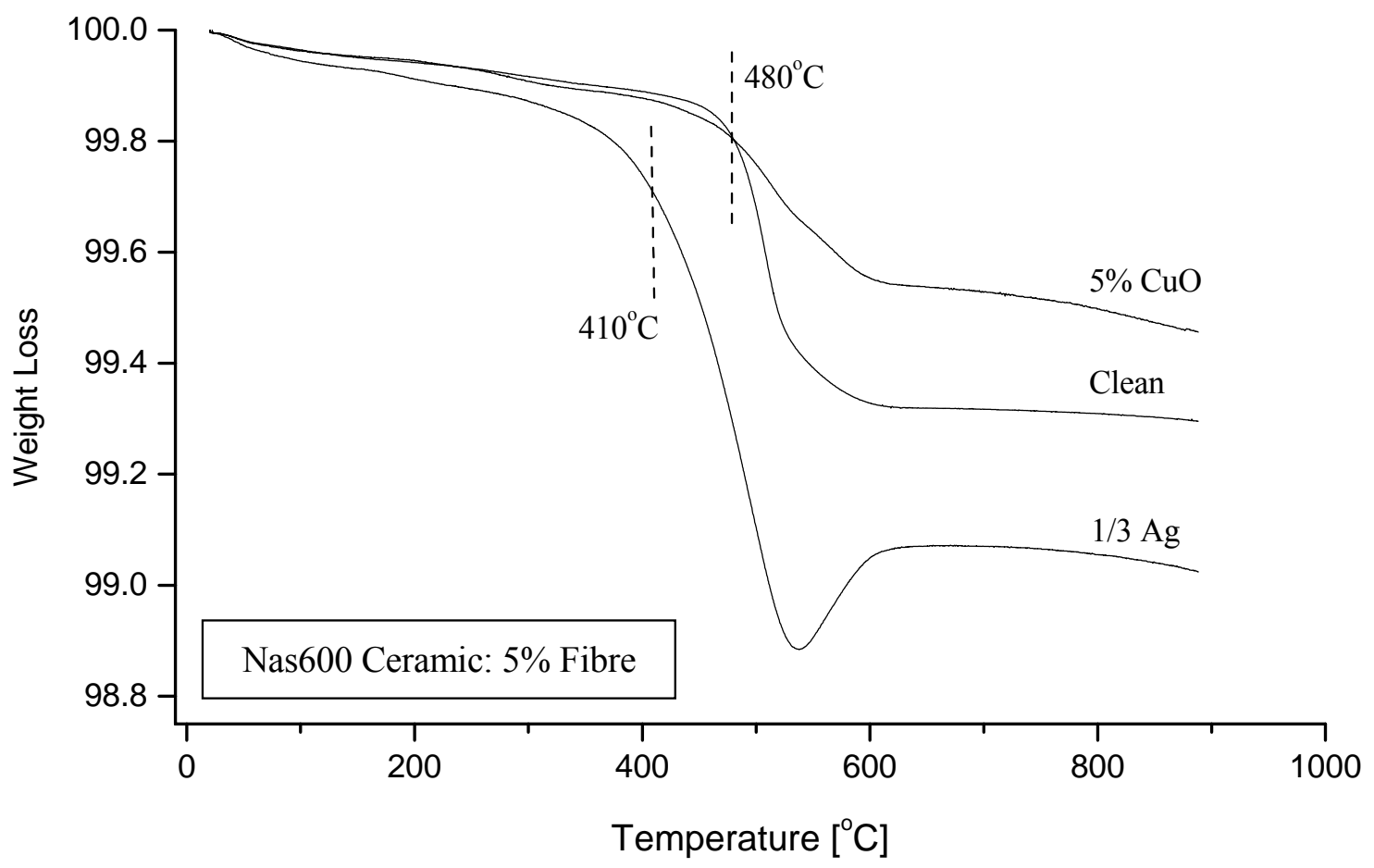

Figure 6

TGA curves for the NASICON composition (Nas600). Curves for compositions containing 5\% $\mathrm{CuO}$ and clean NASICON (no additives) indicate no reduction of the oxidation temperature at which the carbon black begins to oxidize associated with copper doping. 


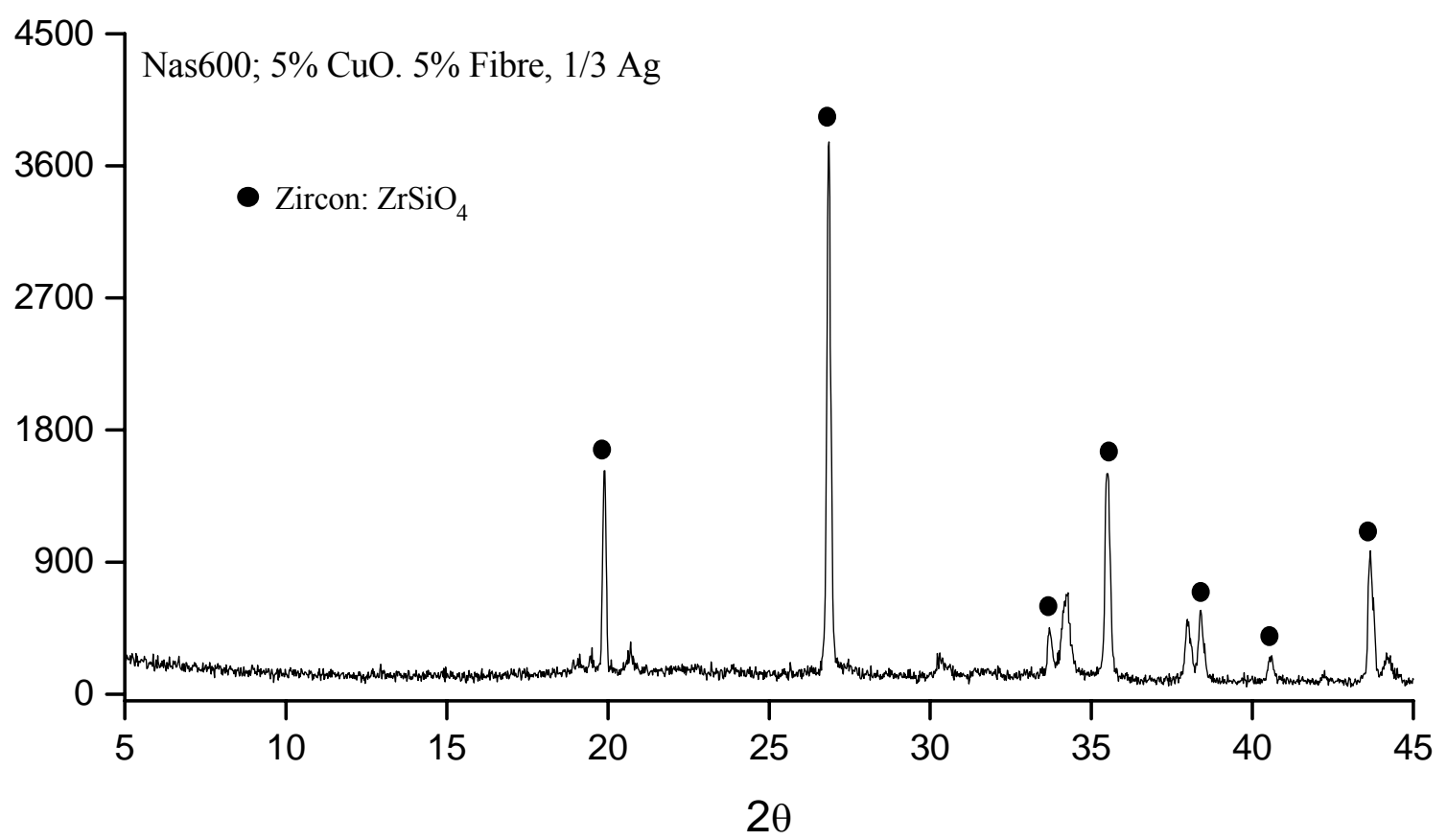

Figure $7 \mathrm{a}$

The $\operatorname{Nas}(1 / 3 \mathrm{Ag})$ and $\mathrm{Nas}(2 / 3 \mathrm{Ag})$ compositions formed zircon as the only crystalline phase. 


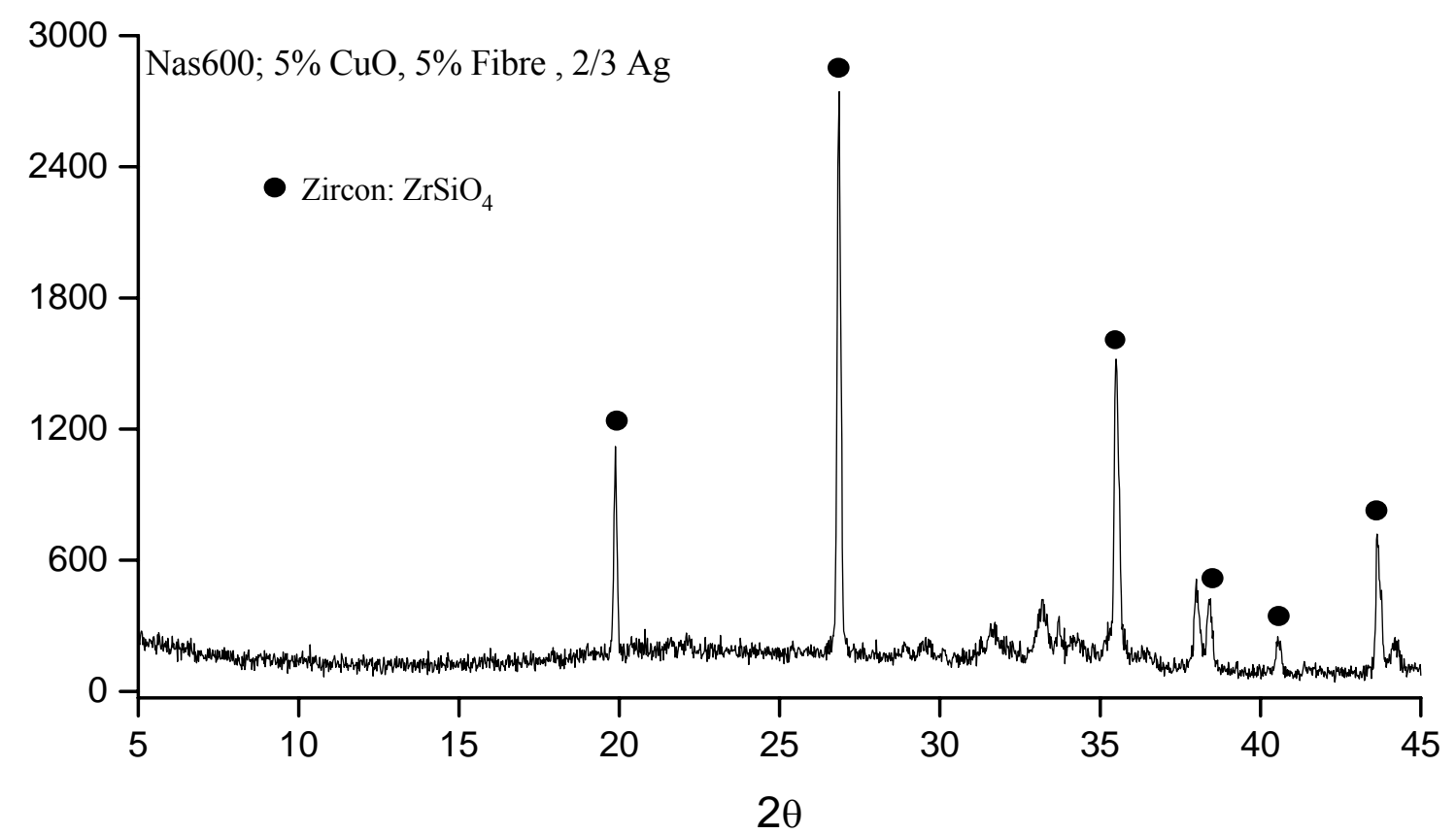

Figure $7 b$

The $\operatorname{Nas}(1 / 3 \mathrm{Ag})$ and $\operatorname{Nas}(2 / 3 \mathrm{Ag})$ compositions formed zircon as the only crystalline phase. 


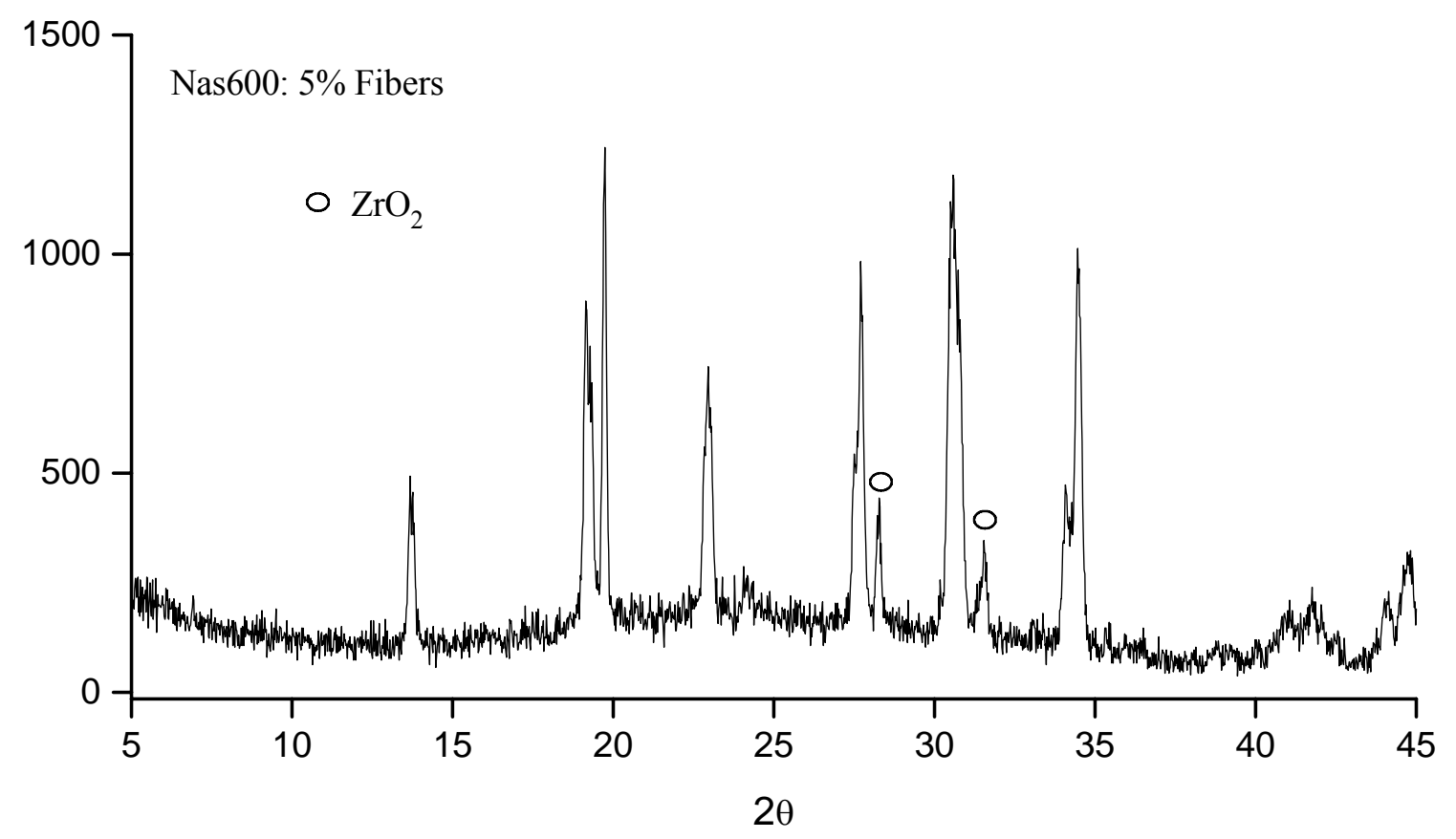

Figure 8a

The XRD pattern of Nas( $600 ; 5 \%$ fiber $)$. 


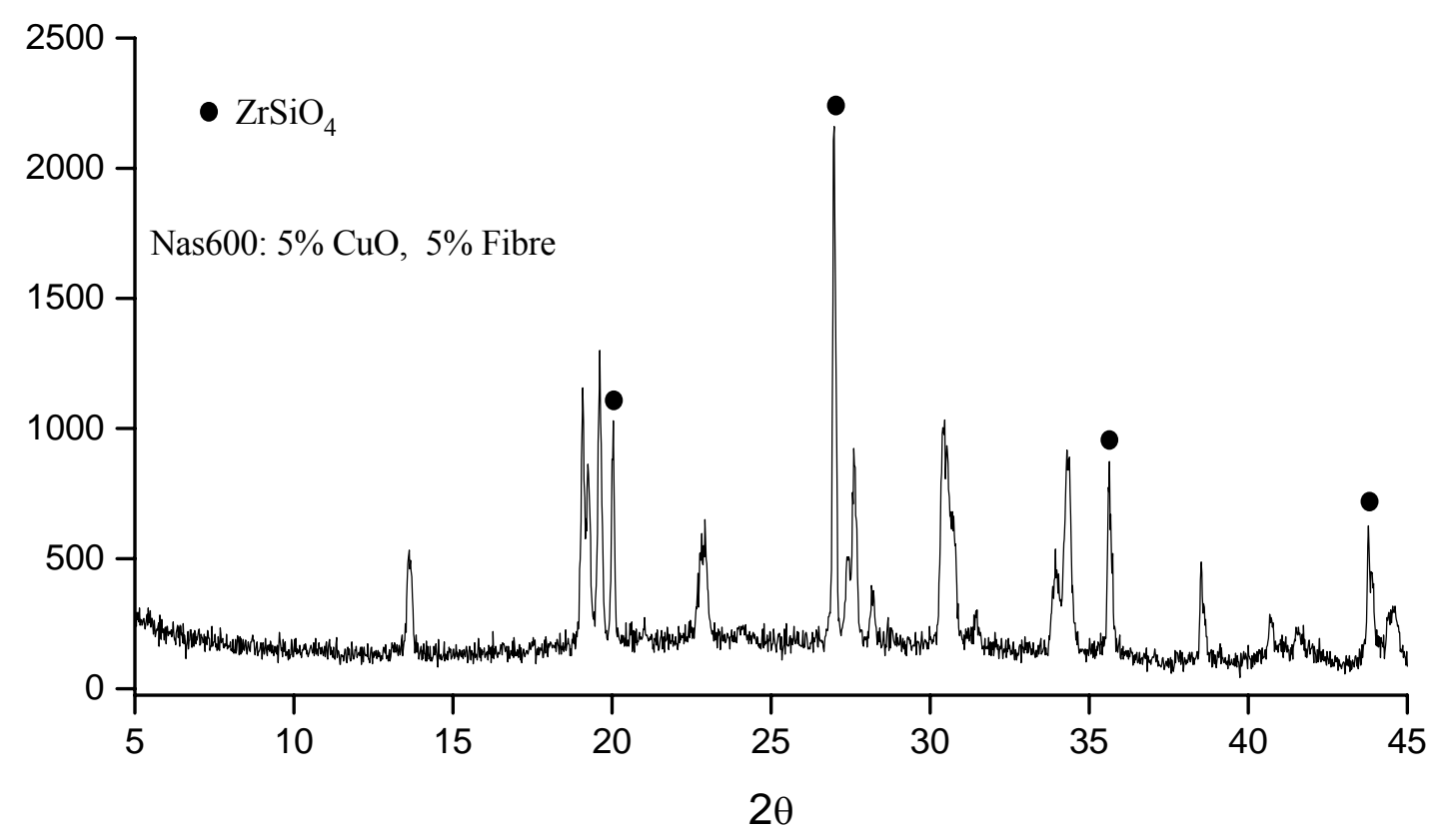

Figure $8 b$

The XRD pattern of Nas $(600 ; 5 \% \mathrm{CuO}, 5 \%$ fiber $)$ shows this composition to be bi-phasic and to contain zircon. 


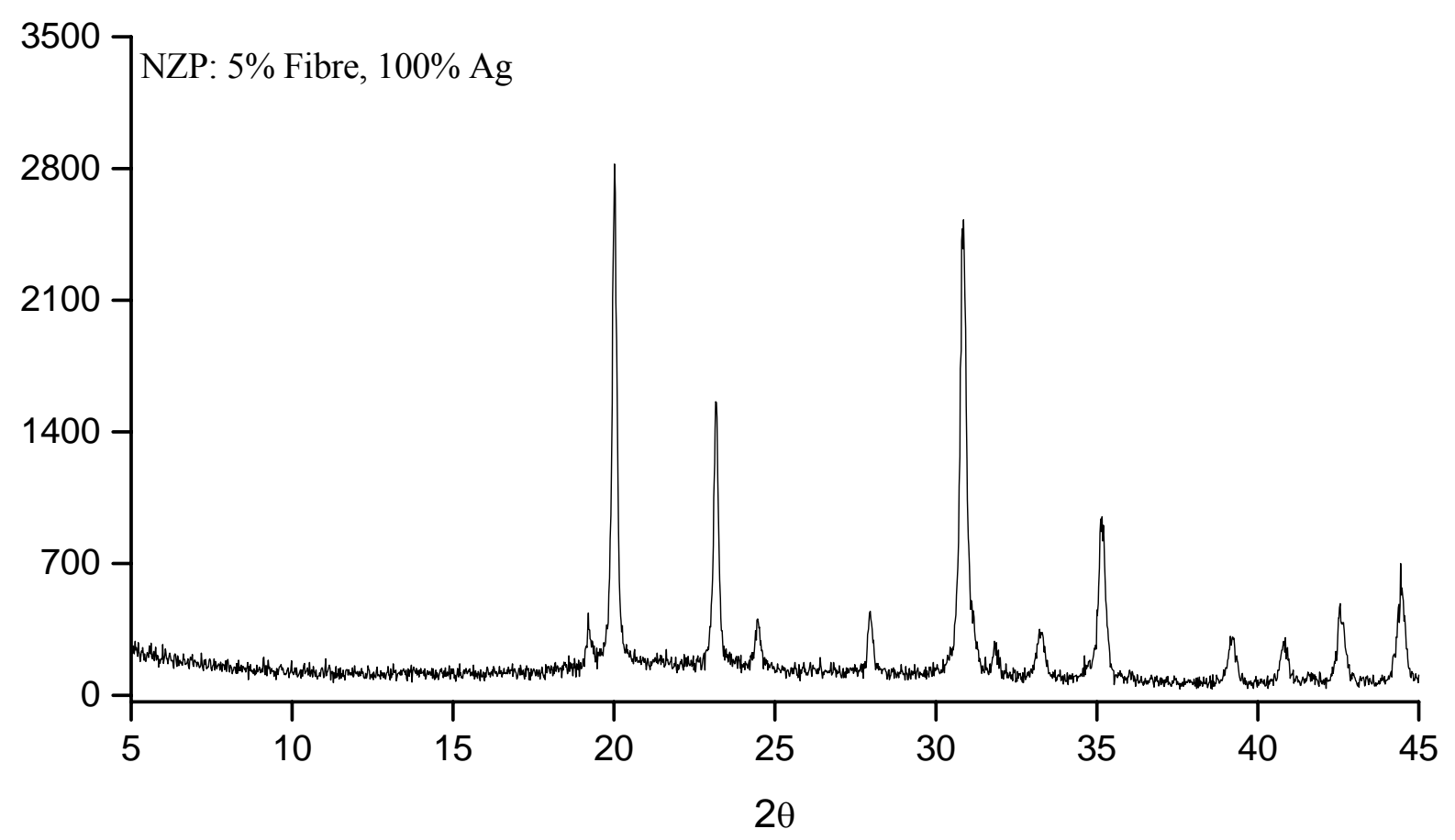

Figure 9

Ag can substitute completely into the NZP structure and the XRD pattern of phase-pure $\mathrm{AgZr}_{2}\left(\mathrm{PO}_{4}\right)_{3}$ is shown. 


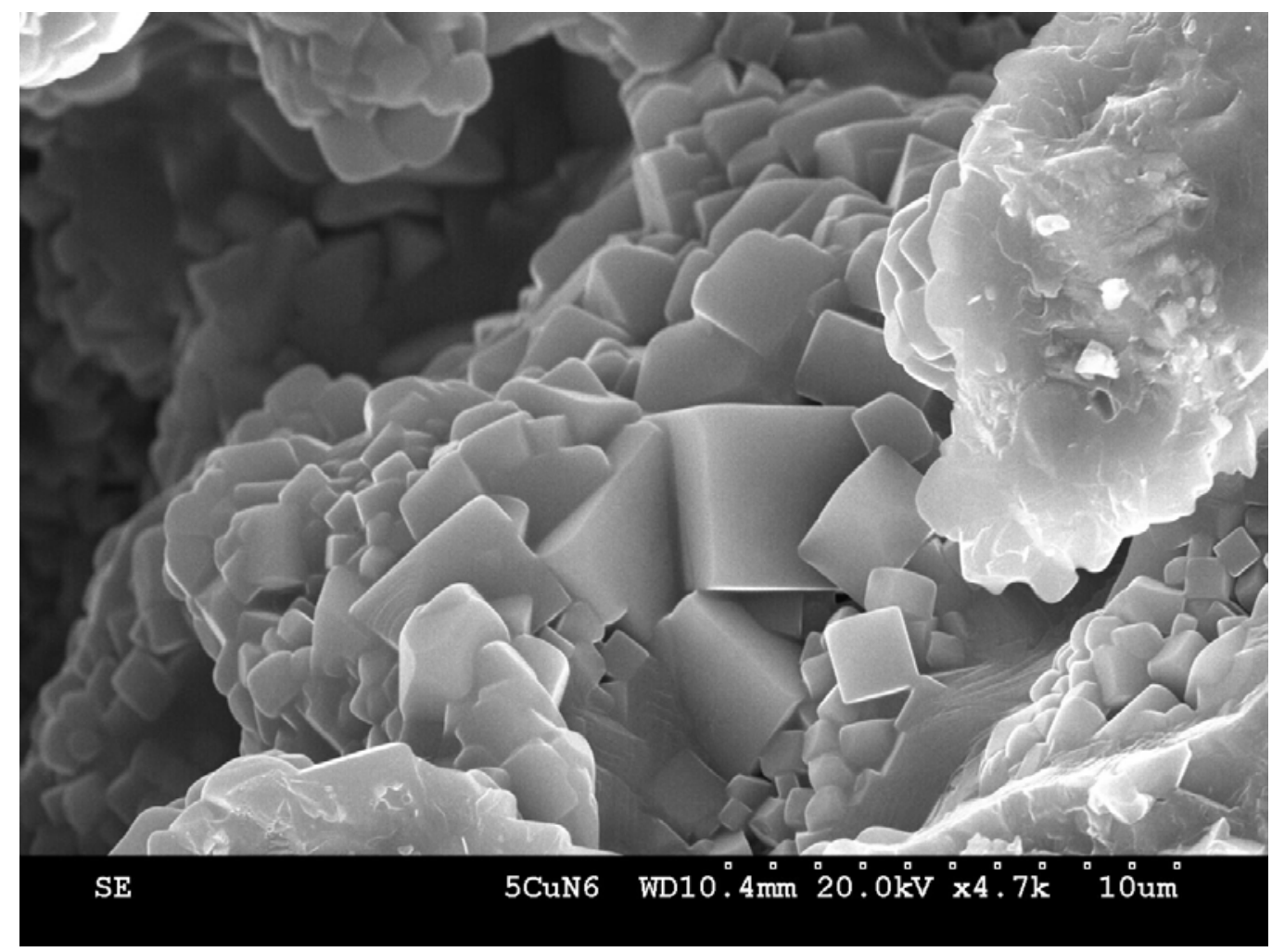

Figure 10

Nas600 (5\%CuO, 5\%Fibres) shows well developed crystallites. 


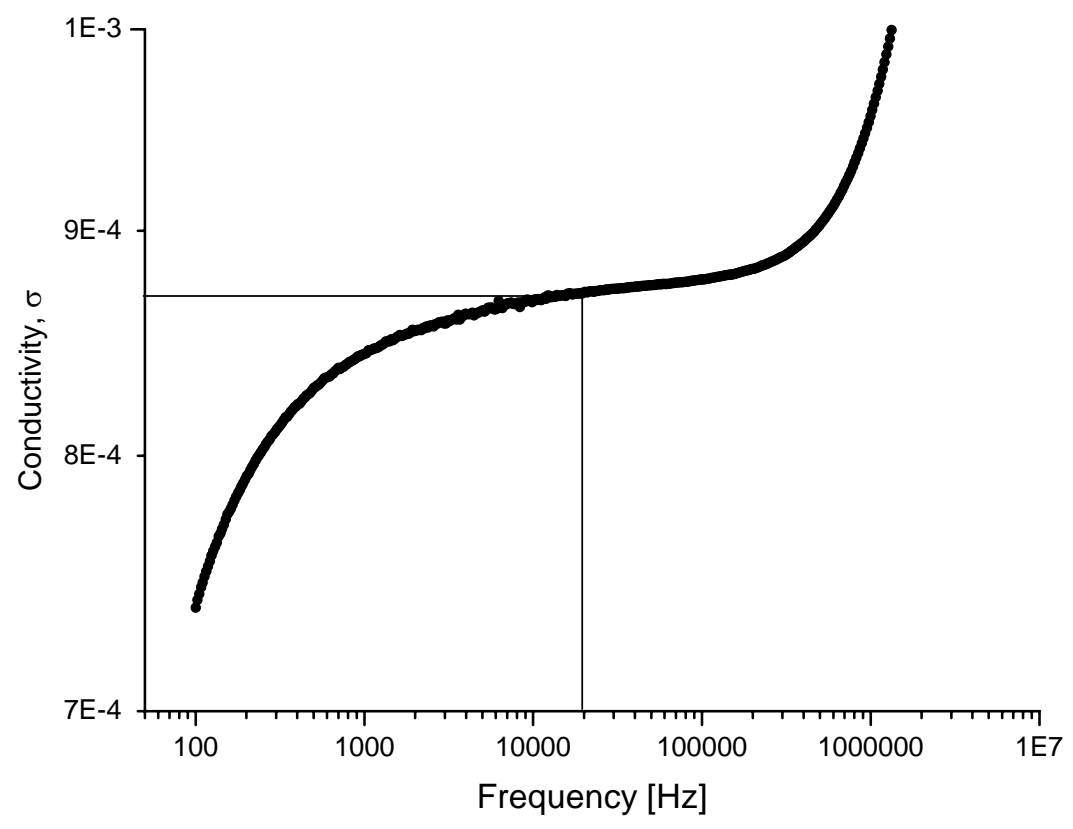

Figure 11

A typical plot log-conductivity vs log-frequency from measurements taken at $80^{\circ} \mathrm{C}$. The DC conductivity was taken as the value corresponding to the frequency independent. 


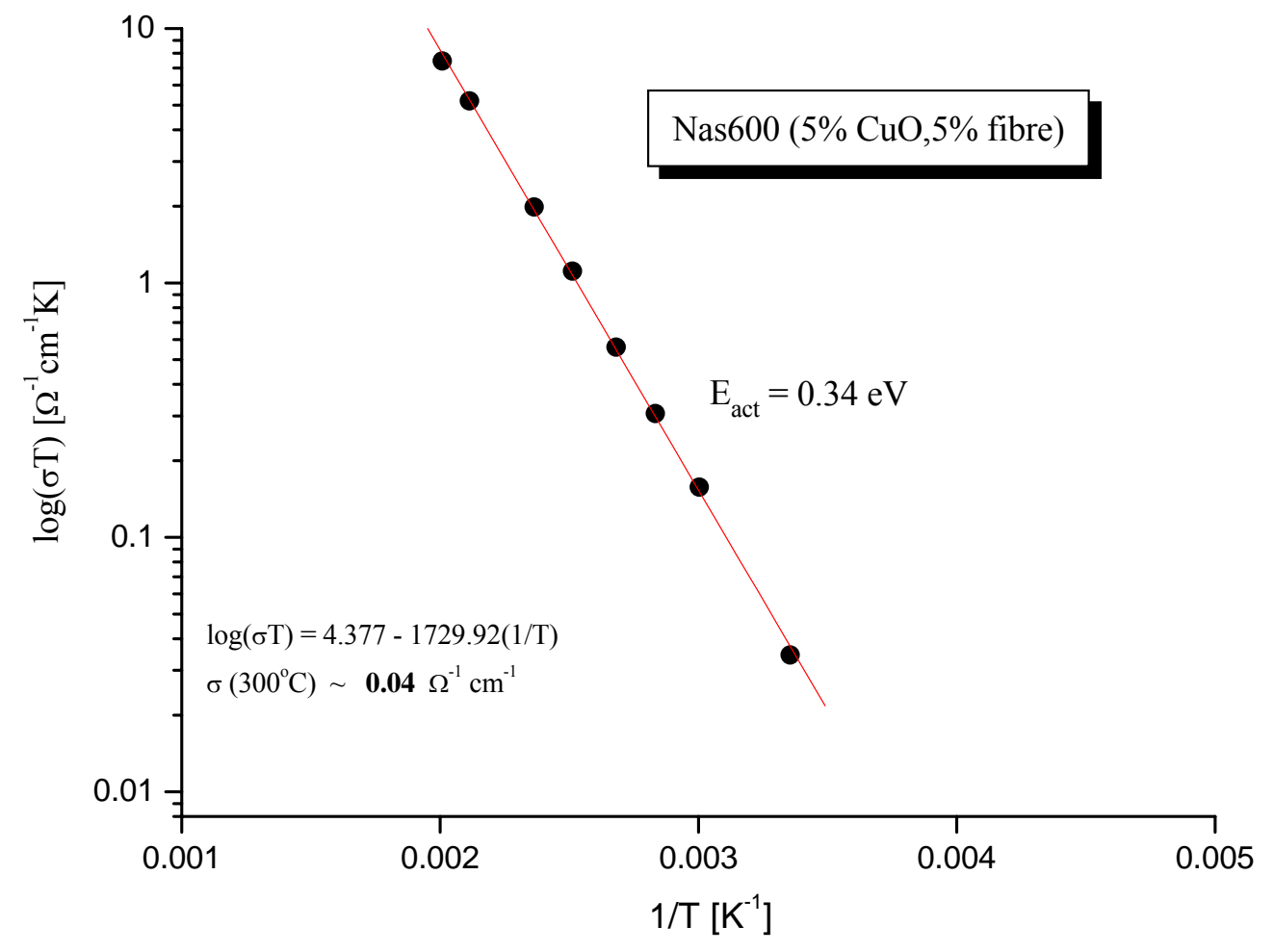

Figure 12

Conductivities at a frequency of $20,000 \mathrm{~Hz}$ plotted as a function of inverse temperature to establish the activation energy as a measure of mobility of the sodium ion. 